\title{
Ana e Mia na "nova” rede: comunidades reúnem anoréxicas e bulímicas na Web 2.0
}

\author{
Vanessa Alkmin Reis ${ }^{1}$
}

\section{Resumo}

O artigo pretende, através de uma contextualização histórica, situar o movimento pró-anorexia e pró-bulimia difundido na Internet como um dos fenômenos característicos da cultura contemporânea, em muito pautada pela velocidade dos fluxos de informação e pela organização em rede. Partimos de um mapeamento cronológico da Internet, desde seu surgimento aos dias atuais, com a chamada Web 2.0. Em seguida, procedemos a uma descrição do movimento pró-ana e pró-mia, através de pesquisa empírica em diversos sites e comunidades virtuais. Por fim, desenvolvemos uma análise deste fenômeno, enfatizando sua relação com a rede e a cultura que proporcionaram seu desenvolvimento e expansão.

Palavras-chaves: Internet, web 2.0, pró-ana/pró-mia.

\begin{abstract}
The article seeks, through a historical contextualization, to situate the pro-anorexia and pro-bulimia movement broadcasted on the Internet as one of the characteristic phenomena of the contemporary culture, remarkably influenced by the speed of the information flows and network organization. We start with a chronological survey of the Internet, since its debut to present day, with the so-called Web 2.0. Then we proceed to a description of the pro-ana and pro-mia movement, through empirical research on several sites and virtual communities. Finally, we have developed an analysis of this phenomenon, emphasizing its relation to the network and culture that provided its development and expansion.
\end{abstract}

Keywords: Internet; web 2.0; pro-ana/pro-mia 


\section{A "nova" rede}

"The web is no longer linking information. Web 2.0 is linking people. People sharing, trading and collaborating.",

Interatividade, compartilhamento de informações e colaboração são termos utilizados desde o surgimento da Internet. A rede que conhecemos hoje, derivada da ARPAnet do Departamento de Defesa dos Estados Unidos na época da guerra fria, sempre teve na descentralização um de seus pontos essenciais. Para além de garantir o funcionamento dos sistemas de segurança, caso um dos "nós" fosse bombardeado, esta ausência de um centro de comando, já por volta de 1960, é a base para compreendermos muitos dos atributos da rede mundial de computadores, bem como da própria sociedade contemporânea.

Com a expansão da Internet, a transmissão de informações em tempo real alcançou dimensões mundiais, possibilitando a passagem de um modelo majoritário de comunicação um-todos, no qual poucos receptores tinham nas mãos a responsabilidade e o poder de transmitir mensagens a toda a sociedade, para um modelo todos-todos, no qual cada cidadão com acesso aos meios é ao mesmo tempo produtor e receptor de um fluxo constante de informações. No capitalismo industrial, os fluxos de informação, trabalho e capital eram organizados no tempo e no espaço pelos Estados nacionais, que exerciam papel regulador. Com a globalização, o papel dos atores na sociedade passou a ser determinado não apenas por sua proximidade com relação aos fluxos informacionais, mas também por sua capacidade de produzir e regular seus próprios fluxos. (Elhajji, 2000: 54-55)

"Pois o homem, (...) diferentemente das criaturas simplesmente biológicas, possui um aparato de transmissão e transformação baseado em sua capacidade de armazenar experiência. E esta capacidade de armazenar - como na própria linguagem, de resto - é também um meio de transformar a experiência” (McLuhan, 1964: 79)

Assim, tal popularização das redes de computadores modificou não apenas a esfera técnica, mas a própria maneira do ser humano perceber o mundo que o rodeia. A partir do desenvolvimento das novas tecnologias de informação e comunicação (NTICs) até mesmo as relações sociais e de produção foram rearticuladas. A sociedade deslocou suas formas de organização política e econômica da dimensão espacial de seu próprio território para a dimensão temporal da velocidade elétrica. Independente do quão imerso cada um de seus segmentos está na tecnologia, todo o conjunto social é afetado pelas inovações propiciadas pela expansão mundial das redes, pois, segundo McLuhan, “os efeitos da tecnologia não ocorrem aos níveis das opiniões e dos conceitos: eles se manifestam nas relações entre os sentidos e nas estruturas da percepção, num passo firme e sem qualquer resistência”. (McLuhan, 1964: 34)

Além de ser o meio pelo qual os dados são transmitidos, as tecnologias adequam-se ao conceito de McLuhan que afirma que "o meio é a mensagem". A mecanização, independente de seus produtos, introduziu em seu tempo o raciocínio seqüencial, através da fragmentação dos processos e posterior seriação das partes 
fragmentadas. Já “o cinema, pela simples aceleração mecânica, transportou-nos do mundo das seqüências e dos encadeamentos para o mundo das estruturas e das configurações criativas" (McLuhan, 1964: 26). Do mesmo modo, a tecnologia de redes informatizadas que vemos surgir torna-se o próprio paradigma da comunicação na sociedade contemporânea. Independente de seu conteúdo, ela própria difunde e legitima a predominância dos valores ocidentais, desde o alfabeto, do jeito como o conhecemos, até os valores abstratos, como a velocidade, o imediatismo e o consumo. (Elhajji, 2000: 49)

"Reunir-se à distância, ou ainda, estar tele-presente, ao mesmo tempo aqui e ali, constituem tão somente as características disseminadas pelas novas tecnologias da comunicação e da informação, onde a interatividade, a imediatez e a ubiqüidade surgem como a verdadeira mensagem da emissão e da recepção em tempo real. Um tempo real que, na verdade, nada mais é do que um espaço-tempo real, uma vez que as interações sociais ocorrem de fato, tem o seu lugar, mesmo se, no fim das contas, esse lugar é o não-lugar da velocidade." (Ferreira, 2005: 6)

Com isso, coloca-se em prática novas formas de pensar os conceitos de comunidade e sociabilidade, cada vez mais dissociados dos fatores tempo e espaço. As novas tecnologias de informação e comunicação (NTIC) proporcionaram o advento da comunicação assíncrona, possibilitando assim que indivíduos em pontos diversos do globo, vivendo em fusos horários diferentes, possam trocar mensagens entre si sem a necessidade de estar conectados um com o outro em tempo real. Ao mesmo tempo, com as mudanças sociais decorrentes da urbanização e modernização tecnológica, a proximidade geográfica deixou de ser determinante na formação das redes sociais. Para isso, as tecnologias da Internet, como listas de discussão, sites de relacionamento e programas de comunicação instantânea, facilitaram a aproximação de pessoas com idéias semelhantes, independente de sua localização geográfica. “(...) o que observamos em nossas sociedades é o desenvolvimento de uma comunicação híbrida que reúne lugar físico e ciber lugar (para usar a terminologia de Wellman) para atuar como suporte material do individualismo em rede." (Castells, 2003: 108).

Atualmente, a Internet vive um momento que alguns especialistas consideram a "segunda geração" da rede. Após a expansão inicial acelerada (entre 1990 e 2000) e posterior enfraquecimento, com grandes perdas econômicas para muitos que decidiram investir no emergente segmento online, a web continua demonstrando seu caráter de renovação constante. Além de não ter fracassado, como previam alguns pessimistas, ela demonstra a cada dia que suas principais características vieram não somente para facilitar a relação do homem com a máquina, mas para serem marcas registradas do estilo de vida de sociedades inteiras neste início de século XXI.

Durante uma reunião da empresa norte-americana O’Reilly Media ${ }^{3}$, o termo Web 2.0 foi utilizado pela primeira vez para se referir à tendência predominante na Internet contemporânea: a ênfase em comunidades, serviços e aplicativos centrados no usuário. A popularização da banda larga possibilitou o acesso de um número cada vez maior de pessoas a recursos antes restritos a grandes corporações e provedores de serviços. 
Em novembro de 2006, 74\% dos 14,4 milhões de usuários ativos da internet brasileira usavam uma conexão de alta velocidade para navegar na internet ${ }^{4}$. Este número corresponde a 10,7 milhões de brasileiros com velocidade de conexão suficiente para capacitá-los a diversas atividades antes impossíveis, como compartilhar arquivos, produzir e difundir conteúdo.

A controvérsia gerada pelo termo envolve, de um lado, os entusiastas da "nova geração" da internet e, de outro, pessoas que acreditam que a ampla utilização do termo web 2.0 seja uma jogada publicitária, uma buzzword para atrair a atenção do público. Contendas à parte, a expressão consegue englobar uma série de conceitos-chave para entender o que é a Internet hoje. A transição para um modelo de comunicação todostodos é exemplificada por Renê de Paula Jr, em entrevista ao site Web2.0Br: "na web 2.0 não somos mais caçadores / coletores. Temos nome, plantamos conteúdo, colhemos conhecimento e criamos novos mundos." Apesar da alusão ao estabelecimento humano em um território fixo expressa na metáfora, estamos virtualmente mais nômades do que nunca. Pode-se circular de uma página a outra através de eficientes sistemas de busca orientados por tags, palavras segundo as quais os próprios usuários classificam o que é postado na rede, como pegadas deixadas para outros que vierem depois em busca do mesmo caminho.

O conteúdo é cada vez mais personalizado e, uma vez tirado das mãos de grandes empresas, reforça a tendência ao domínio público, exemplificado pelos movimentos de software livre e licenças abertas de direito autoral. A web é vista como uma plataforma, um meio para que os serviços atinjam cada vez mais internautas. É a inteligência coletiva delas que possibilita o aperfeiçoamento constante dos programas, partindo do princípio de que ter milhares de pessoas atentas a erros e munidas dos meios para consertá-los, ao invés de apenas uma empresa e sua equipe de suporte técnico, aumenta as chances de que esta falha seja corrigida.

A ênfase na construção colaborativa deu origem a sites como a Wikipedia ${ }^{6}$, enciclopédia aberta em que qualquer pessoa pode postar ou editar artigos. A plataforma escrita a milhares de mãos conta hoje com mais de dois milhões de textos em língua inglesa. Em português, são mais de 350 mil artigos que, embora ainda sejam encarados com certa desconfiança por alguns, pela falta de garantia de procedência, vêm se tornando a grande fonte e o grande retrato da sabedoria das multidões na web.

O e-mail, os blogs e fóruns de discussão foram os precursores da conversa online, que agora encontra espaço em sites de redes sociais. Ferramentas amigáveis dispensam conhecimentos técnicos para a criação de um espaço pessoal na internet, ao qual se permite o acesso de amigos, familiares e até mesmo curiosos. Tecnologias como a programação XML e a distribuição de conteúdo RSS combinam as facilidades de dois ou mais sites na mesma interface, e possibilitam que o conteúdo, previamente selecionado por tags, venha até o usuário antes mesmo que ele o procure. Assim, cada vez mais incentiva-se a interação, motivada principalmente por gostos e interesses pessoais comuns. 


\section{Ana e Mia na rede}

A internet, por seu próprio caráter descentralizado e não-regulamentado, tornou-se um meio de comunicação propício ao encontro de pessoas com interesses comuns, dos mais variados tipos. Com isso, abrese espaço nos fluxos informacionais da rede para os mais diversos tipos de pensamentos, ideologias e grupos, que aí encontram os meios para expressar suas idéias e localizar partidários das mesmas causas em qualquer lugar do mundo.

A alegação da busca de um corpo ideal é um dos motivos citados por milhares de pessoas, na maioria mulheres jovens, que adotam comportamentos classificados pela medicina como transtornos alimentares particularmente a anorexia e a bulimia - como "estilos de vida". Dizendo-se adeptas da frase "os fins justificam os meios", elas praticam a recusa à comida e/ou a purgação do alimento ingerido como formas de atingir um tipo físico compatível com certo padrão de beleza, seja ele o divulgado pela sociedade ou, mais frequentemente, um padrão auto-imposto de magreza extrema.

Protegidas pelo anonimato da rede, as seguidoras da Ana e da Mia (apelidos carinhosos dados, respectivamente à anorexia e à bulimia) encontraram em blogs, fóruns e sites de relacionamento lugares nos quais poderiam falar sobre uma parte de suas vidas que, na maioria das vezes, é vivida em silêncio: a relação complicada com a alimentação e a imagem corporal.

Assim, surgiu o movimento pró-anorexia e pró-bulimia na internet, no ano 2000. Inicialmente difundida nos Estados Unidos e Inglaterra, a tendência não demorou a chegar a outros países, como acontece com quase tudo na atual cultura globalizada. No Brasil, os blogs pró-ana/mia apareceram em 2002. Dois anos mais tarde, com a criação e popularização do site de relacionamentos Orkut, foram criadas comunidades virtuais para reunir as bulímicas e anoréxicas, tanto aquelas que estão em tratamento quanto as que querem continuar nestas condições.

Já na fase inicial de pesquisa em que nos encontramos, algumas características do movimento analisado são delineadas, permitindo-nos identificar um perfil padrão entre as pessoas que acessam os sites pró-ana e pró-mia. A grande maioria é composta de mulheres. A participação de homens nestas comunidades é bastante reduzida, porém existente. Isso reflete a própria estatística dos transtornos alimentares, que revela que, dentre os pacientes, apenas 10\% são do sexo masculino. A maior incidência desses distúrbios nas mulheres é atribuída a fatores hormonais, sociológicos, psicológicos, e bioquímicos, como a maior propensão feminina a distúrbios do metabolismo de serotonina.

A maior parte dos acessos é de jovens, particularmente na fase os 13 e os 17 anos de idade. Como, essencialmente, as usuárias destas páginas e comunidades virtuais se apresentam com um perfil falso, para não serem facilmente identificadas por amigos e parentes, esta observação é feita com base na idade informada em seus blogs e perfis. Além disso, indícios de adolescência podem ser verificados na escrita tipicamente 
“internética", com diminutivos, abreviações, letras repetidas e formatações destacadas, como negrito, itálico e fontes coloridas. Com freqüência aparecem nos perfis fotografias de ídolos teen, particularmente os que já tiveram algum histórico de transtornos alimentares, como a cantora Anahí, do grupo RBD, e a atriz Nicole Richie.

A inspiração por celebridades é outro traço marcante nas páginas ana e mia. Muitas afirmam que a sociedade lhes impõe que sejam magras, que vêem dia após dia que só as magras conseguem popularidade, respeito, sucesso amoroso e aceitação. Como exemplo disso, estampam em seus espaços virtuais imagens de atrizes e modelos donas de corpos - e, consequentemente, de modos de vida - perfeitos. Embora as mulheres idolatradas possam variar um pouco, dependendo da nacionalidade da blogueira, algumas como Angelina Jolie e Victoria Beckham são praticamente unanimidades. Os homens também têm seus "musos" inspiradores: famosos magros como Daniel de Oliveira (especialmente na interpretação de Cazuza, no filme de mesmo nome) e Daniel Radcliffe, intérprete do bruxo Harry Potter no cinema. Popular também é a tatuagem de Angelina Jolie com os dizeres latinos quod me nutrit, me destruit - em português, o que me alimenta me destrói. Várias garotas relatam o desejo de tatuar em seus corpos a mesma frase, algumas realmente o fizeram.

Juntamente com as fotografias, os lemas compõem parte importante das chamadas thinspirations, as inspirações de magreza postadas na rede. Frases como "se é saboroso, está tentando te matar", "um minuto na sua boca, a vida toda no seu quadril" e "um corpo imperfeito reflete uma pessoa imperfeita" demonstram, ao mesmo tempo, profunda insatisfação com o corpo que possuem e a obsessão pelo que o corpo pode vir a se tornar, seguindo este estilo de vida. Sentenças como essas viram títulos de blogs, posts, comunidades, e são mescladas a fotografias de pessoas magras em vídeos motivacionais compartilhados online.

Até um objeto de identificação foi criado para que elas possam reconhecer-se umas às outras no meio da multidão. As anas, partidárias da anorexia, usam pulseiras vermelhas, feitas com miçangas, fitas ou qualquer outro material. As mias, favoráveis à bulimia, pulseiras roxas. Os acessórios passam despercebidos para quem não conhece o significado, mas garantem à usuária que, uma vez que aviste no shopping ou na escola alguém com uma pulseira semelhante, pode trocar um olhar de cumplicidade ou até mesmo receber, numa situação difícil, o mesmo apoio tantas vezes encontrado somente no mundo virtual. Outra utilidade atribuída ao acessório é servir como um lembrete do compromisso com a Ana e a Mia. A orientação de algumas garotas é colocar a pulseira na mão usada para abrir a geladeira. Assim, ao olhar para a bijuteria, reafirmariam sua recusa à comida e desistiriam da refeição.

O padrão de magreza extrema é considerado o ideal pelas anas e mias, embora elas mesmas reconheçam que ele desagrada a muitos. Frases como "não importa o que falem, vou atingir minha meta" são bem comuns nas comunidades virtuais. A opinião de familiares, amigos e parceiros amorosos, de que elas já estariam magras demais, são consideradas meras tentativas de demovê-las de seus objetivos. Nas comunidades pró-ana e mia, ao contrário, tais pessoas encontram exatamente o que gostariam de ouvir: frases como "nunca 
se está magra demais" e incentivos para deixar "os ossinhos aparecerem" funcionam como combustível para a luta incessante contra a comida. Os objetivos de peso são quase irreais. Muitas garotas almejam pesar por volta de 35 quilos. A insatisfação constante é uma marca nos perfis observados. Por mais baixo que seja o peso, uma vez atingido, uma nova meta é estabelecida e a busca continua.

Sintomas como fraqueza, tontura e desmaios são valorizados como indícios de vitória. A comunidade Estar fraca é ser forte reúne 260 membros com a seguinte descrição: "Depois de dias de LF, ou (principalmente) $N F$, bate aquela tontura, você perde o equilíbrio, a vista escurece, dá uma fraqueza... Só mostra o quanto você foi forte por ter agüentado até ali!” A morte, que acomete cerca de $10 \%$ dos pacientes diagnosticados com estes transtornos alimentares, é considerada uma consequiência indesejada, mas não um empecilho. Pessoas mortas em decorrência de anorexia e bulimia, como a modelo Ana Carolina Reston, falecida em 2006 com peso corporal de 40 quilos, são reverenciadas por muitas como "mártires da causa". Os tópicos de discussão demonstram que a grande maioria das anoréxicas e bulímicas tem consciência de que o mesmo pode vir a acontecer a elas, mas a declaração mais freqüente é a disposição para "morrer lutando".

\section{Pró-ana e pró-mia como fenômeno da cibercultura}

Impondo a velocidade, a internet ostenta a bandeira do próprio modo de vida ocidental. Ela modifica a inserção das pessoas em suas relações de sentido, sua forma de percepção e suas interações sociais, que passam a ser pautadas, independente do território onde acontecem, pelos valores ocidentais de imediatismo e consumo. As fronteiras, antes físicas, passam a ser "eletro-cognitivas ou cogni-computacionais” (Elhajji, 2000: 47)

“As coordenadas dessa esfera cognitiva, contudo, correspondem, rigorosamente, aos pontos de projeção dos planos éticos e estéticos do Ocidente. No processo de transferência de nossos mapas semânticos da dimensão espacial para a temporal, pois, o Ocidente não se apresenta mais como região geográfica, mas sim como fato semiótico ou espectro cognitivo, cujos contornos não são mais espaciais, mas sim teóricos, epistemológicos, técnicos e tecnológicos." (Elhajji, 2000: 47)

Além dos discursos difundidos em rede, sua própria estrutura tecnológica contribui para a construção desta nova semiose, reproduzindo e induzindo a determinadas atitudes frente ao outro, seja ele semelhante ou diferente, próximo ou distante.

“A globalização seria menos a instalação material da rede mundial do que a generalização e universalização de seu modelo tecnológico e lingüístico como paradigma das comunicações humanas. A globalização / ampliação da noosfera ocidental não está na rede / Internet, mas sim é a própria rede / Internet como modelo universal de comunicação. Não apenas ela veicula um discurso, mas sim é em si discurso globalizante e ocidentalizante." (Elhajji, 2000: 49) 
A velocidade dos fluxos de informação em rede impõe-se, cada vez mais, como o ritmo que pauta a vida. Modifica nossa forma de ver o mundo, de sentir o tempo, de manter relações com outros seres humanos. Define experiências e relativiza conceitos, permeando, assim, toda a existência daqueles que navegam em sua "correnteza caótica de homens e coisas" (Carvalho apud Santaella, 2004: 29) "Que faz a velocidade? Ela desestrutura o processo de percepção, comprimindo o tempo, até chegarmos a um tempo único e global, e desconstrói o espaço. Cumprem-se os nossos sonhos de criança: tornamo-nos fluidos e multidimensionais." (Mourão, 2004, online)

Nas comunidades virtuais, a anorexia e a bulimia são também defendidas como estilos de vida, e não como condições dignas de tratamento médico. A noção de estilo de vida denota a fluidez da sociedade contemporânea, em lugar das identidades mais ou menos delimitadas que marcaram a modernidade.

"Em linhas gerais, o estilo de vida reflete a sensibilidade (ou a "atitude") revelada pelo indivíduo na escolha de certas mercadorias e certos padrões de consumo e na articulação desses recursos culturais como modo de expressão pessoal e distinção social. (...) É constituído por imagens, representações e signos disponíveis no ambiente midiático e, em seguida, amalgamados em performances associadas a grupos específicos.” (Freire Filho, 2003)

Os padrões de grupo são importantes também para proporcionar conforto e sensação de proteção, em uma época de insegurança generalizada causada pela falta de diretrizes e instituições sólidas. A cultura de maximização do corpo eleva sua importância como valor pessoal, disseminando a idéia de conquista da felicidade através da aquisição da constituição física perfeita. “Assim, o corpo e todo o instrumental utilizado para projetá-lo como símbolo de poder passam a ser perseguidos como bens simbólicos, na tentativa de neutralizar o mal-estar gerado pela fragmentação da identidade.” (Andrade e Bosi, 2003)

O movimento pró-ana e pró-mia encontrou nas próprias características da "nova geração" da web um terreno fértil para vir a público. Se as doenças em si já têm um longo registro na história médica, a organização de pessoas que desejam tê-las ou, no mínimo, apóiam quem tenha, surgiu nos fóruns abertos da rede. Em blogs, listas de discussão e páginas de relacionamento, os partidários da causa fazem uso do poder depositado pela internet contemporânea nas mãos do usuário comum.

As comunidades de anas e mias no Orkut, por exemplo, já passam de três centenas. Nos tópicos são comuns as temporadas de no food (NF) e low food (LF) coletivos, em que as garotas organizam uma rede de apoio mútuo para incentivar as outras durante o tempo de restrição alimentar. Dicas para esconder melhor o problema, aliás, é um dos assuntos mais acessados pelas anoréxicas e bulímicas. Sugestões como levar o aparelho de som para o banheiro ou ligar o chuveiro para abafar o som dos vômitos, enviadas por pessoas que passam pela mesma situação, geram um clima de compreensão, conforto e aceitação que geralmente não é sentido no convívio social das meninas.

Vários textos são publicados em perfis, páginas pessoais, blogs e repassados na internet como "literatura" do movimento pró-ana e mia. Um dos mais difundidos nas comunidades é a carta de uma suposta 
anoréxica hospitalizada, que ilustra o desejo da magreza última, cadavérica, ao afirmar que nunca se sentiu tão bem quanto agora, que pode contar todos os ossos do corpo, e que se sente como um anjo leve pronto para voar.

Muito populares também são a Carta da Ana e a Carta da Mia, repetidas em quase todas as comunidades observadas. Funcionam como uma espécie de "carta de apresentação" da anorexia e da bulimia, mostrando, principalmente às iniciantes, os benefícios que podem proporcionar a quem a elas recorrer: perfeição corporal (Ana) e socorro nos episódios de compulsão (Mia).

O movimento a favor da anorexia e da bulimia chegou também a sites de compartilhamento de vídeos, como o Youtube. Uma busca simples pelas tags "pro ana mia" no portal de vídeos apresenta cerca de 600 resultados. Entre eles estão reportagens de TV referentes ao tema, vídeos caseiros com opiniões individuais e muitas tentativas de conscientização e alerta para os perigos deste tipo de conduta. A maioria dos vídeos encontrados, porém, se encaixa no que as garotas chamam de thinspiration, inspirações magras. São montagens feitas a partir de fotos e vídeos, geralmente combinados com uma música de fundo, retratando mulheres extremamente delgadas. Grande parte das imagens é de modelos e atrizes famosas, consideradas donas de corpos perfeitos. Mas encontram lugar também thinspirations baseadas em fotos de pessoas reais, que funcionam para elas como prova de que, através destes comportamentos alimentares, garotas comuns podem chegar cada vez mais perto do que consideram perfeição.

\section{Considerações finais}

A disponibilidade da Internet torna visível o movimento pró-anorexia e bulimia como um fenômeno característico de nosso tempo, em que todos podem ser produtores e divulgadores de conteúdos, com todos os aspectos positivos e negativos que esta abertura acarreta. Isto posto, alguns questionamentos se fazem necessários para aqueles que almejam entender, através de exemplos como este, uma parte da cultura veloz e fluida em que estamos imersos.

A internet, bem como as demais tecnologias de comunicação e informação, permeia todos os campos da sociedade contemporânea com seu sem-número de possibilidades. Diante da quantidade de informações disponíveis, e dos meios ofertados para a difusão dos mais diversos tipos de conteúdo, cabe questionar o papel da web na construção de comportamentos, gostos, pensamentos e atitudes. Acreditamos que reflexão e estudo isentos, sérios e livres de julgamento de valor, por parte de profissionais de todos os campos do conhecimento e da cultura, podem fazer com que avancemos alguns passos na compreensão desta e de outras nuances do ser humano contemporâneo. Apresentar alguma contribuição a este avanço é o que pretendemos com a continuidade desta pesquisa. 


\section{Referências bibliográficas}

ANDRADE, Angela; BOSI, Maria Lúcia Magalhães. Mídia e subjetividade: impacto no comportamento alimentar feminino. In: Revista de Nutrição, Campinas, 16(1): 117-125, jan/mar, 2003.

CASTELLS, Manuel. A galáxia da Internet. Rio de Janeiro: Jorge Zahar Editor, 2003.

ELHAJJI, Mohammed. Globalização \& Novas Tecnologias de Comunicação. In: Lumina 4. Juiz de Fora v. 3, n. 1, p. 45-64, jan-jun. 2000

FERREIRA, Leonardo Teixeira de Mello. Comunicação e velocidade - O novo espaço-tempo da interação social. In: XXVIII CONGRESSO BRASILEIRO DE CIÊNCIAS DA COMUNICAÇÃO, 2005, Rio de Janeiro. Anais. Rio de Janeiro: [s.n.], 2005.

FREIRE FILHO, João. Mídia, consumo cultural e estilo de vida na pós-modernidade.

Revista ECO-PÓS. Rio de Janeiro: UFRJ, v. 6, n. 1, p. 72-97, 2003.

MCLUHAN, Marshall. Os meios de comunicação como extensões do homem. São Paulo: Cultrix, 1964.

MOURÃO, José Augusto. O mundo das redes: a euforia rizomática. Cadernos do Instituto São Tomás de

Aquino, Lisboa, 2004. Disponível em http://www.triplov.com/ista/cadernos/mundo_das_redes.html

SANTAELLA, Lúcia. Navegar no ciberespaço: o perfil cognitivo do leitor imersivo. São Paulo: Paulus, 2004

\footnotetext{
${ }^{1}$ Mestranda em Comunicação e Sociedade. Universidade Federal de Juiz de Fora (UFJF). vanessareis84@gmail.com

${ }^{2}$ Trecho extraído do vídeo "The machine is us/ing us (final version)”. Disponível em http://www.youtube.com/watch?v=NLlGopyXT_g

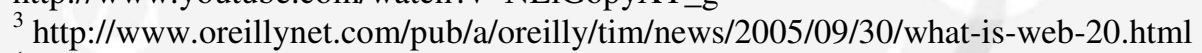

${ }^{4}$ http://idgnow.uol.com.br/internet/2007/01/05/idgnoticia.2007-01-04.2426042674/

${ }^{5}$ http://web2.0br.com.br/conceito-web20/

${ }^{6}$ http://www.wikipedia.org/
} 